\title{
Neural Network-based Sliding Mode Control for Permanent Magnet Syn- chronous Motor
}

\author{
Kaiqi Huang ${ }^{1,2, *}$ and Shilin $\mathrm{Zuo}^{2}$
}

\begin{abstract}
${ }^{I}$ School of Mechanical and Automotive Engineering, South China University of Technology, Guangzhou Guangdong, 510640, China

${ }^{2}$ School of Mechanical and Electrical Engineering, Jiangxi university of Science and Technology, Ganzhou, Jiangxi, 341000, China
\end{abstract}

\begin{abstract}
In this paper, a scheme of designing neural network-based sliding mode controller is proposed for dealing with the chattering phenomenon existing in conventional sliding mode controller because of its discrete control law. Firstly, the sliding mode control law is designed using equivalent control technology. Then the neural network and adaptive control are uesd to delete the chattering of sliding mode controller. The stability of control system is analyzed by Lyapunov stability theory finally. Simulations and experiments demonstrate that the proposed neural network-based sliding mode controller not only achieves better control performance than the conventional sliding mode control system, but also is robust with regard to system parameter variation and external disturbance.
\end{abstract}

Keywords: Neural Network, Sliding Mode Control, Permanent Magnet Synchronous Motor, Chattering, Adaptive Control.

\section{INTRODUCTION}

For its high torque to inertia ratio, high efficiency and high power density, permanent magnet synchronous motor (PMSM) is widely used in the tram, robot, CNC machine tools, medical equipment, etc. However, the actual parameters of permanent magnetic synchronous motor system and external disturbance factors affect system performance. Characteristic of time-varying to system parameters and strong robustness toward external disturbances of the sliding mode control provides an effective way for servo systems high-performance control. But the traditional ideal sliding mode controller output is high-frequency positive-negative switching value, and the actual system executing agencies at the time delay and the spatial lag results in that the actual sliding mode doesn't accurately occur in the given switching manifolds surface, easily leading to a system chattering [1]. This also limits the application of sliding mode control method in the actual system.

At present, there are mainly three ways to cut down chattering except for adopting modern control theories, such as adaptive and fuzzy $[2,3]$ to deal with chattering phenomenon: regularization method within the boundary layer [4]; observing the chattering by status observer to realize dynamic sliding mode controller [5, 6]; using high-order sliding mode control algorithm [7]. Although the use of such methods can weaken chattering to some extent, there are still some problems: regularization method within the boundary layer and adjustment method based on observer do not have traditional sliding mode control robustness anymore and at the same time allow the system to hold a steady-state error [8, 9]. High-order sliding control algorithm is complex. In loworder (first or second order) system control law, there exists a coupling between controller output signal and its derivative, which is not conducive to the design of sliding mode control law [10-14].

This paper provides a sliding control strategy based on neural network, considering permanent magnetic synchronous motor system time-varying and external load disturbances. For traditional chattering in an integer order sliding mode control system, adding restriction to sliding control output and using Neural Network algorithm to implement compensation, then the strategy can not only save the sliding mode control technologies robustness, but effectively reduce the chattering. This control strategy has been successfully applied to the permanent magnet synchronous motor speed control and reached a relative high level in the control performance.

\section{PMSM MODEL DESCRIPTION}

Mathematical model of permanent magnet synchronous motor in rotating coordinate system [12]:

$$
\left\{\begin{array}{l}
u_{q}^{*}=R_{s} i_{q}^{*}+\dot{\lambda}_{q}+\omega_{f} \lambda_{d} \\
u_{d}^{*}=R_{s} i_{d}^{*}+\dot{\lambda}_{d}-\omega_{f} \lambda_{q} \\
\lambda_{q}=L_{q} i_{q}^{*} \\
\lambda_{d}=L_{d} i_{d}^{*}+L_{m d} I_{d f} \\
\omega_{f}=n_{p} \omega_{r}^{*}
\end{array}\right.
$$


where, $u_{d}^{*}, u_{q}^{*}$ are the stator voltages under $d, q$-coordinates; $i_{d}^{*}, i_{q}^{*}$ are stator current; $\lambda_{d}, \lambda_{q}$ are stator flux linkage; $L_{d}, L_{q}$ are inductive component; $\omega_{f}, \omega_{r}^{*}$ respectively are motor electrical angle and the given speed; $L_{m d}$ is the stator phase inductance; $I_{d f}$ is equivalent current; $n_{p}$ is the number of stator pole pairs; $R s$ is stator resistance.

Electromagnetic torque equation:

$T_{e}=3 n_{P}\left[L_{m d} I_{d f} i_{q}^{*}+\left(L_{d}-L_{q}\right) i_{q}^{*} i_{d}^{*}\right] / 2$

Dynamic equation:

$T_{e}=J \dot{\omega}_{r}+B_{m} \omega_{r}+T_{l}$

where, $T_{l}$ is loading moment, $B_{m}$ is friction coefficient, $J$ is rotational inertia.

By applying vector control, dynamic equations can be simplified as follows

$$
\left\{\begin{array}{l}
T_{e}=k_{p} i_{q}^{*} \\
k_{p}=3 n_{p} L_{m d} I_{d f} / 2
\end{array}\right.
$$

The dynamic equation (4) into the electromagnetic torque equations (2), the follow equations can be obtained:

$\dot{\omega}_{r}=-a \omega_{r}+b i_{q}-c$

There, $a=\frac{B_{m}}{J}, b=\frac{k_{p}}{J}, c=\frac{T_{l}}{J}$.

Considering the parameters change, the above formula can be expressed as:

$\dot{\omega}_{r}=-(a+\Delta a) \omega_{r}+(b+\Delta b) i_{q}-(c+\Delta c)$

where, $\Delta a, \Delta b, \Delta c$ are system parameter perturbation.

Controller is designed to find a suitable control laws and make the system output $\omega_{r}$ quickly follow the input $\omega_{r}^{*}$. Here define the velocity error: $e(t)=\omega_{r}^{*}(t)-\omega_{r}(t)$, after derivation get:

$\left\{\begin{array}{c}\dot{e}(t)=-a e(t)+\phi(t)+\delta(t) \\ \phi(t)=a \omega_{r}^{*}(t)-b i_{q}(t)+c(t)+\dot{\omega}_{r}^{*}(t) \\ \delta(t)=\Delta a \omega_{r}(t)-\Delta b i_{q}(t)+\Delta c(t)\end{array}\right.$

Assumption is met:

$|\delta(t)| \leq \Psi$

where, $\Psi \in R^{+}$.

\section{SLIDING MODE CONTROLLER DESIGN}

Fractional sliding mode controller design for a two-step: switching manifold face selection and control law design.

This paper select the following switching manifold surface $(s)$ :

$s=k_{p}\left(e(t)+a \int_{0}^{t} e(\tau) d \tau\right)$

where, $k_{p} \in R^{+}$is the sliding mode surface gain.

Control law must be designed to ensure that the system in an arbitrary initial state can reach the sliding state. This paper adopts equivalent control design method.

Conduct the first derivative of the formula (9) and obtain:

$\dot{s}=k_{p}(\dot{e}(t)+a e(t))$

The (7) into above equation, then:

$$
\begin{gathered}
\dot{s}=k_{p}\left(-a e+\delta+a \omega_{r}^{*}-b i_{q}+c+\dot{\omega}_{r}^{*}\right)+a k_{p} e \\
=k_{p}\left(\delta+a \omega_{r}^{*}-b i_{q}+c+\dot{\omega}_{r}^{*}\right)
\end{gathered}
$$

Considering the case of no disturbance $(|\delta(t)|=0)$, and $\dot{s}=0$, Sliding equivalent control law can be obtained:

$i_{q e}=\frac{k_{p}}{b}\left(a \omega_{r}^{*}+c+\dot{\omega}_{r}^{*}\right)$

Use the following switching control law:

$i_{q s}=-\frac{\eta}{b} \operatorname{sgn}(s)$

where, $\eta>k_{p}\left(\Psi+b \varepsilon_{\max }\right)$.

From the above two equations, sliding mode control law was obtained:

$i_{q}=i_{q e}+i_{q s}$
$=\frac{k_{p}}{b}\left(a \omega_{r}^{*}+c+\dot{\omega}_{r}^{*}\right)-\frac{\eta}{b} \operatorname{sgn}(s)$

Considering the chattering, the main reason is that the sliding mode control law output amplitude is too large positive and negative frequency signal, then, the following control law is used to suppress chattering:

$i_{q}=\operatorname{sat}(u)=\left\{\begin{array}{cc}u_{u p}, & u>u_{u p} \\ u, & |u| \leq u_{u p} \\ -u_{u p}, & u<-u_{u p}\end{array}\right.$

$\Gamma=i_{q}-u$ 


\section{NEURAL NETWORK APPROXIMATION ALGO- RITHM DESIGN}

In order to save the strong robustness of sliding mode control technology, at the same time produce no excessive chattering, $u_{u p}$ must be chosen according to the system status. This paper adopts the neural network approximation capability, on-line adjusting the parameters.

Neural network input/output is as follows:

$$
\begin{aligned}
& h_{j}=\exp \left(\frac{\left\|x-c_{i}\right\|^{2}}{2 b_{j}^{2}}\right) \\
& \Gamma=W^{* T} h(x+\varepsilon)
\end{aligned}
$$

where, $x$ is the input of network, $i$ is the $i$-th input of the network input layer, $j$ is the $j$-th input of the hidden layer, $h=\left[h_{j}\right]^{T}$ is the output of the Gaussian basis function, $W^{*}$ is the ideal weights of the network, $\varepsilon$ is ideal neural network approximation error of $\Gamma . \varepsilon \leq \varepsilon_{\max }, \hat{\Gamma}$ is the output of network. $\hat{W}$ is estimate weights of the network

Let neural network input $x=u$, then, the output of the network:

$$
\begin{aligned}
& \hat{\Gamma}=\hat{W}^{T} h \\
& \text { If } \tilde{W}=\hat{W}-W^{*}, \text { then } \\
& \begin{aligned}
\Gamma-\hat{\Gamma} & =W^{* T} h+\varepsilon-\tilde{W}^{T} h \\
& =\left(W^{* T}-\tilde{W}^{T}\right) h+\varepsilon \\
& =-\tilde{W}^{T} h+\varepsilon
\end{aligned}
\end{aligned}
$$

So, control law (16) turns into

$$
\begin{aligned}
u & =i_{q}-\hat{\Gamma} \\
& =\frac{k_{p}}{b}\left(a \omega_{r}^{*}+c+\dot{\omega}_{r}^{*}\right)-\frac{\eta}{b} \operatorname{sgn}(s)-\hat{\Gamma}
\end{aligned}
$$

\section{ADAPTIVE CONTROL DESIGN BASED ON LYA- PUNOV STABILITY}

Select the following Lyapunov function:

$\dot{V}=s \dot{S}+\lambda \tilde{W}^{T} \tilde{\dot{W}}$

The control law (16) into equation (11), obtain

$$
\dot{s}=k_{p}\left(\delta+a \omega_{r}^{*}-b(\Gamma+u)+c+\dot{\omega}_{r}^{*}\right)
$$

Equation (20) into the above equation, obtain

$$
\begin{aligned}
\dot{s} & =k_{p}(\delta-b(\Gamma-\hat{\Gamma}))-\eta \operatorname{sgn}(s) \\
& =-\eta \operatorname{sgn}(s)+k_{p} b \tilde{W}^{T} h-k_{p} b \varepsilon+k_{p} \delta
\end{aligned}
$$

The above equation into equation (21), then

$$
\begin{aligned}
\dot{V}= & s \dot{s}+\lambda \tilde{W^{T}} \tilde{\dot{W}} \\
& =-\eta|s|+s k_{p} b\left(\tilde{W^{T}} h-\varepsilon\right)+s k_{p} \delta+\tilde{\delta} \tilde{W^{T} \tilde{\dot{W}}} \\
& =-\eta|s|+s k_{p} b \varepsilon+s k_{p} \delta+\tilde{W^{T}}\left(s k_{p} b h+\lambda \tilde{\dot{W}}\right)
\end{aligned}
$$

Take the following adaptive control law:

$\tilde{\dot{W}}=-\frac{1}{\lambda} s k_{p} b h$

Then

$$
\dot{V}=-\eta|s|+s k_{p}(b \varepsilon+\delta) \leq 0
$$

Therefore, the system satisfies the stability condition.

\section{SIMULATION RESULTS AND DISCUSSION}

This article is based on permanent magnet synchronous motor servo system speed loop and the step responses of the simulation results are provided respectively based on neural network for adaptive Sliding Mode Controller and the regularization method sliding mode controller[4].

The simulation is based on "Matlab/Simlink" software, adopting permanent magnet synchronous motor servo system speed ring platform as Fig. (1), motor parameters: $R_{s}=1.15$ $(\Omega), \quad L_{d}=L_{d}=8.5 e-3 \quad(\mathrm{H}), \quad n_{p}=4, \quad J=2.5 e-3 \quad\left(\mathrm{~kg} . \mathrm{m}^{2}\right)$, $B_{m}=1.0 e-3$ (N.m.s).

Sine response results of two kinds of sliding mode control system and its corresponding state convergence trajectory as shown in Fig. $(\mathbf{2}, \mathbf{3}, \mathbf{4})$, respectively. From Simulation Results, it can be seen that the proposed neural network adaptive sliding mode control makes system chattering very small after it reaches the sliding mode surface, with the same effect as using regularization method, but the response time is much faster than the regularization method sliding-mode control algorithm resulting in a better overall control performance.

\section{EXPERIMENT}

The proposed control strategy is experimented in PMSM servo system, experimental platform as shown in Fig. (5). Main control board is based on TMS320F2812 DSP processor. The PC mainly captures servo motor feedback data and conducts comparative analysis. The motor parameters and load current $\left(I_{l}\right)$ as follows: $J_{m}=2.5 e-3\left(\mathrm{~kg} \cdot \mathrm{m}^{2}\right)$, $B_{m}=1.0 e-3(\mathrm{~N} \cdot \mathrm{m} . \mathrm{s}), I_{l}=0.0(\mathrm{~A})$.

The experimental results are shown in Fig. (6), as can be seen from it, the rise time of a neural network adaptive sliding mode control system ts $=0.25625 \mathrm{~s}$, by contrast, integer order sliding mode control system rise time ts $=0.4625 \mathrm{~s}$. So the system response speed of the Neural Network Adaptive 


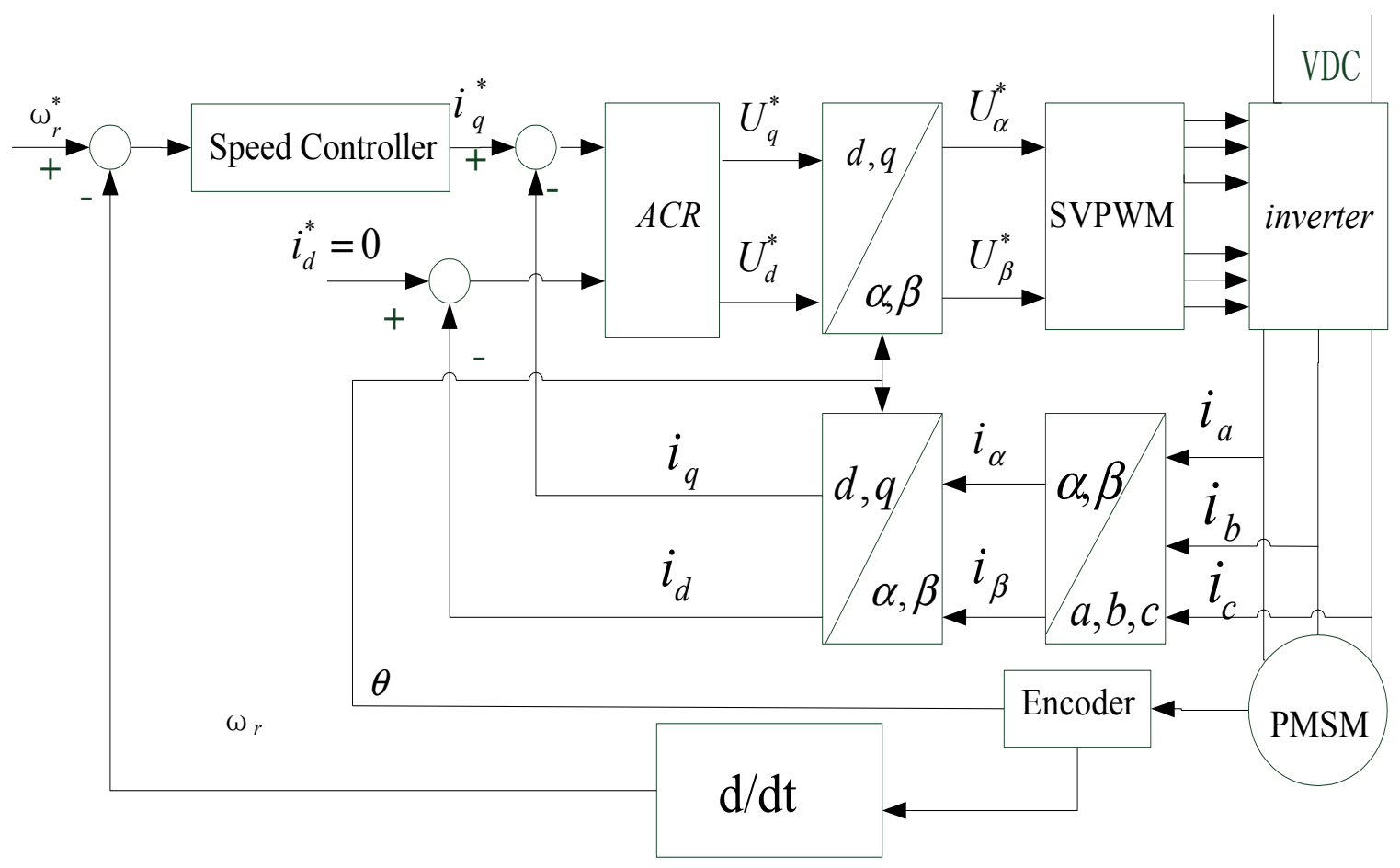

Fig. (1). Speed Loop Model of Servo.
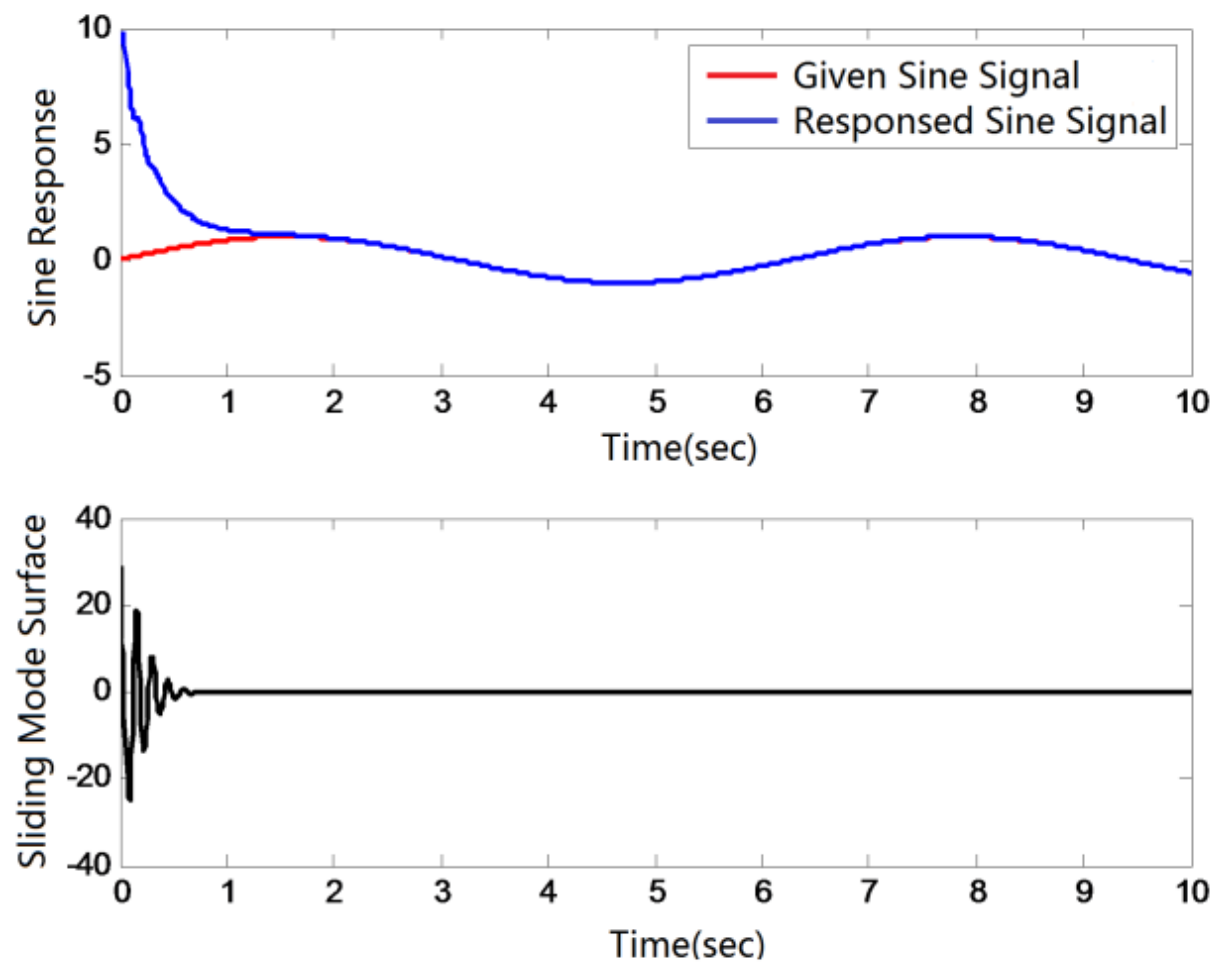

Fig. (2). Sin Response for Neural Network-based Sliding Mode Control System and Switching Surface. 

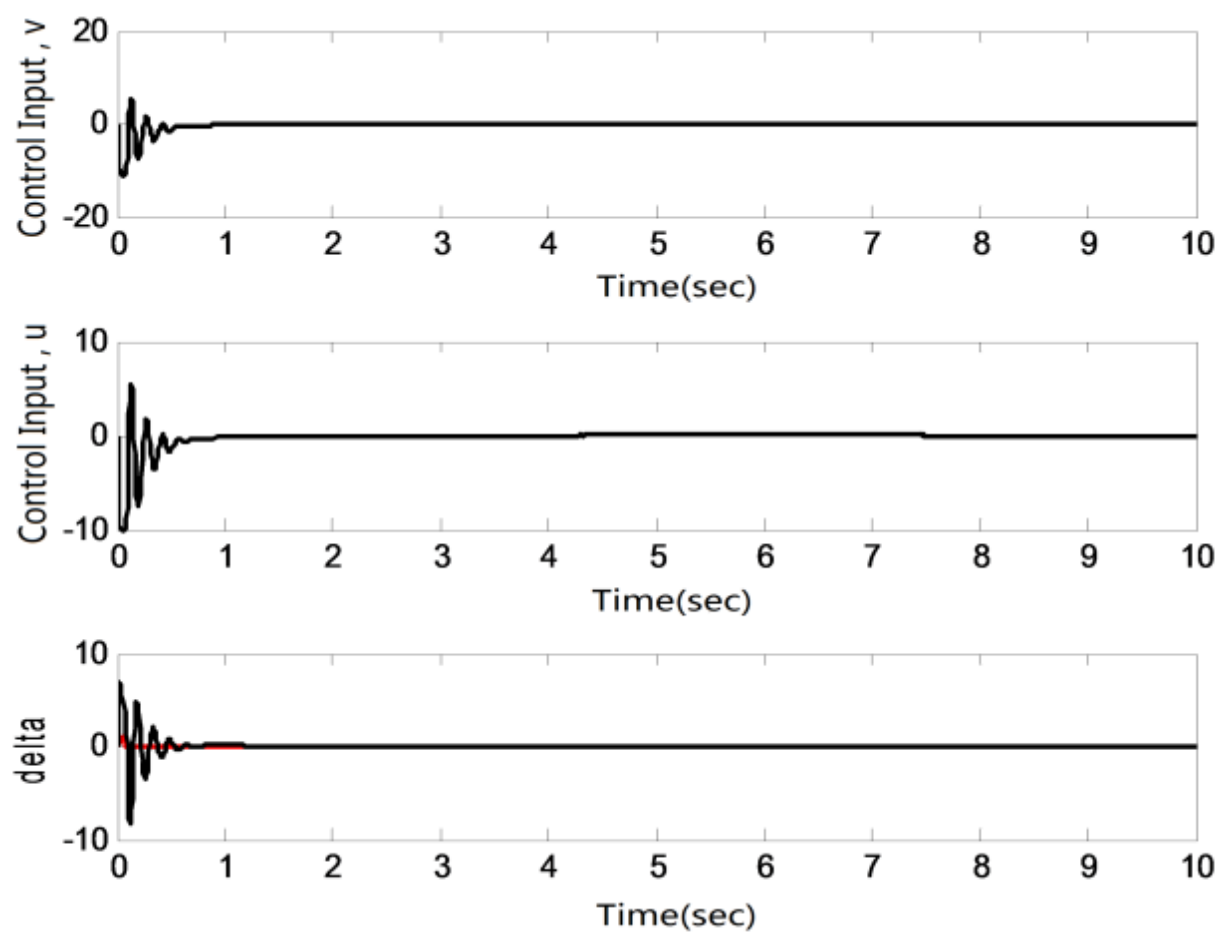

Fig. (3). Control Input of Neural Network-based Sliding Mode Control System.
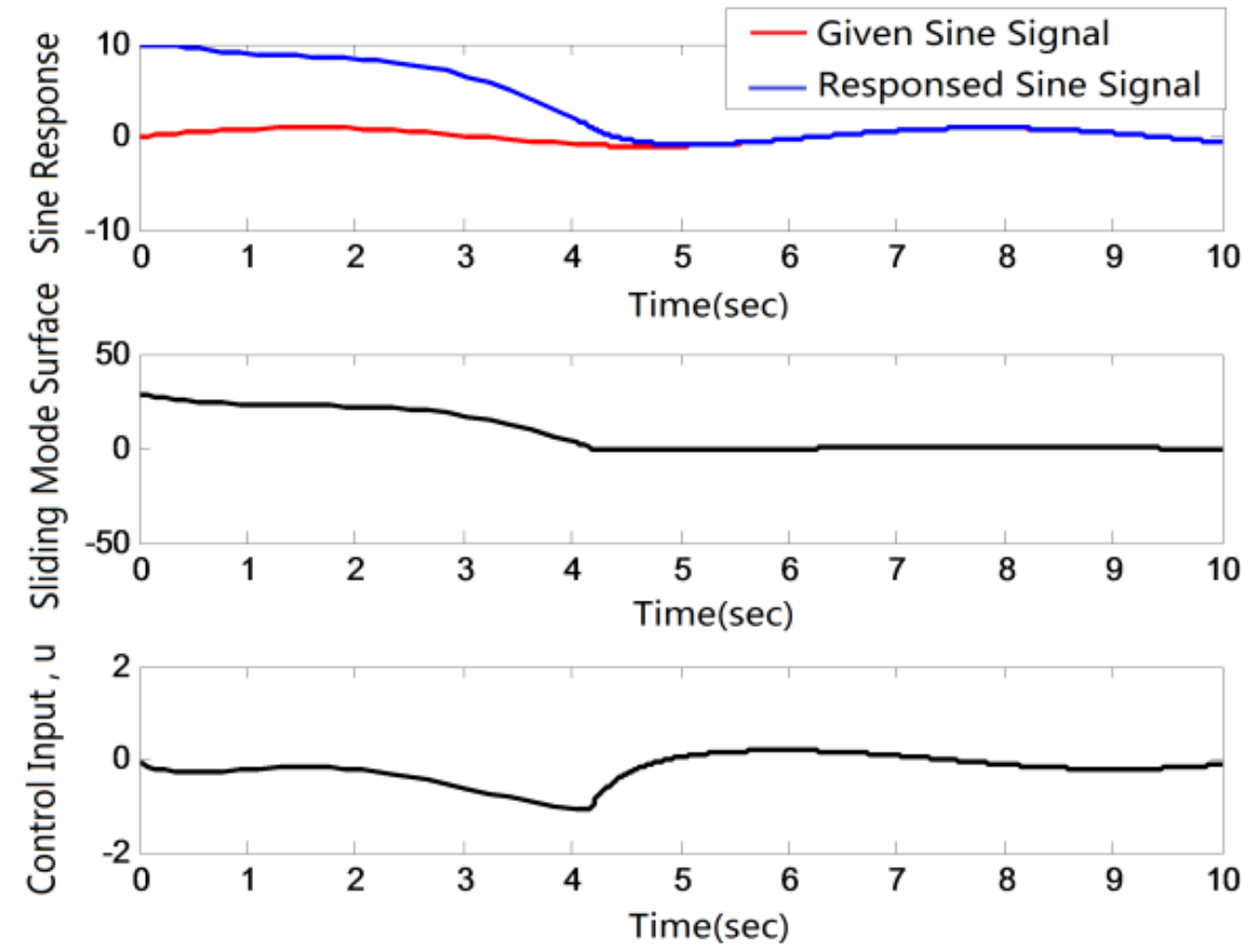

Fig. (4). Using Boundary Layer Integral Sliding Mode Control. 


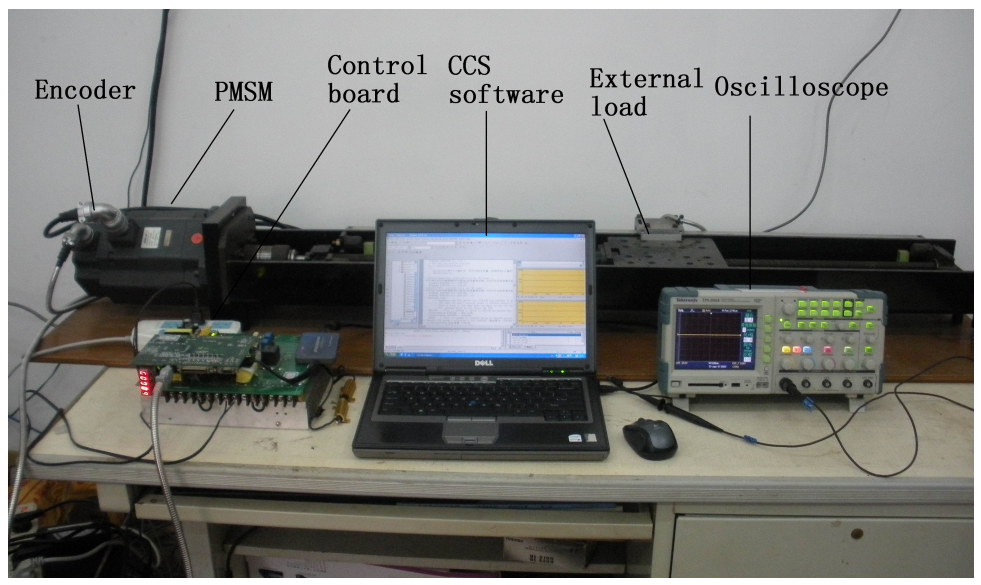

Fig. (5). Experiments Plant.

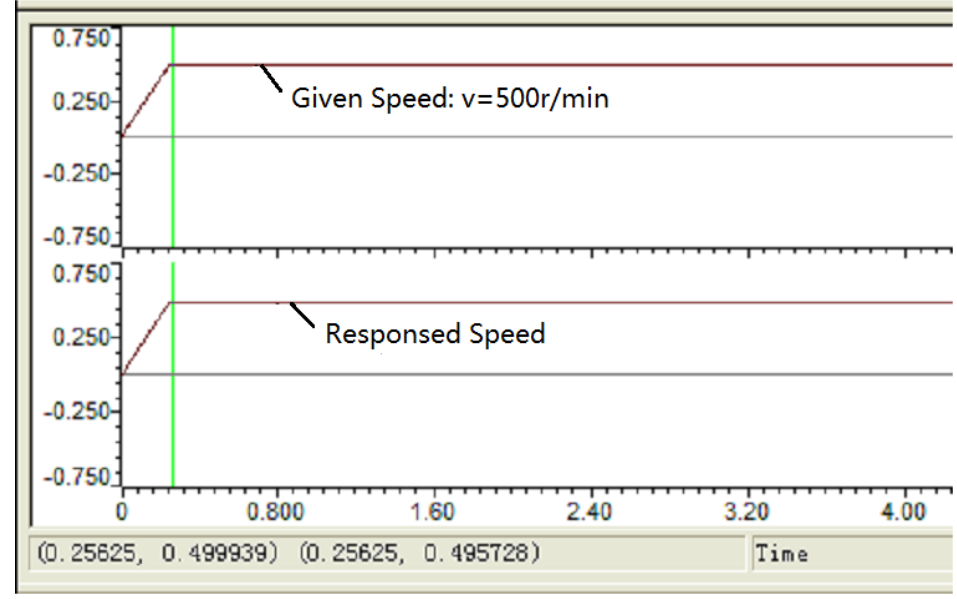

(a) neural network-based sliding mode control

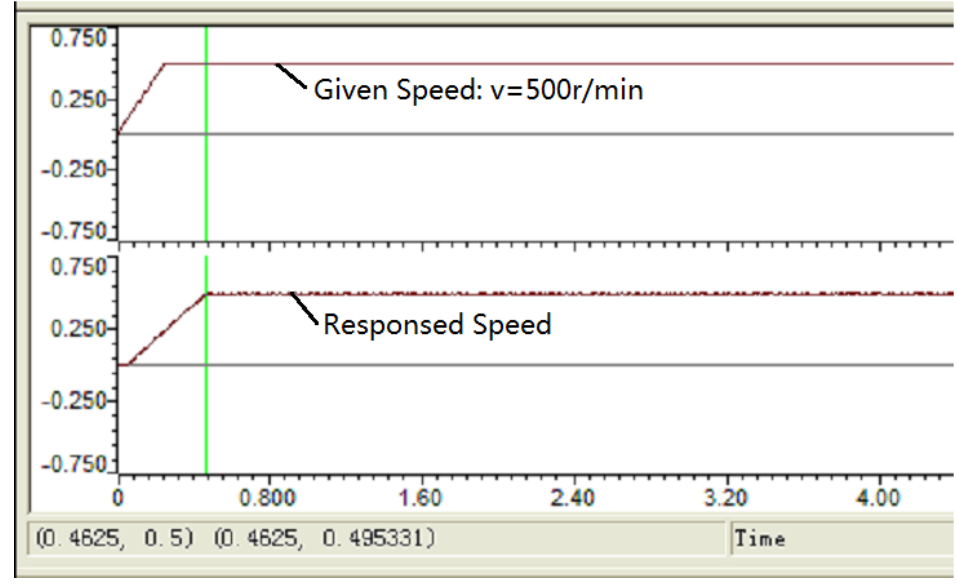

(b) Using boundary layer integral sliding mode control

Fig. (6). Step response.

sliding mode control system is faster than that of the regularization sliding mode control system.

\section{CONCLUSION}

Aiming at chattering problem of traditional integer order sliding mode control systems caused by time-varying parameters and external load disturbance of the the permanent magnet synchronous motor servo system, this paper designs the sliding mode control system based on neural network and adaptive algorithm. Permanent magnet synchronous motor servo system of speed loop simulation and experiments shows that the proposed control strategy not only effectively reduces the chattering in traditional sliding 
mode control system, but achieves higher overall performance by good adaptive ability to parameter variations and external disturbance.

\section{CONFLICT OF INTEREST}

The author confirms that this article content has no conflict of interest.

\section{ACKNOWLEDGEMENTS}

This work is supported by National Nature Science Foundation under Grant (61105085) and Jiangxi Provincial Department of Science and Technology Project ( 20123BBE50085)

\section{REFERENCES}

[1] Y. Hu, "Variable Structure Control Theory and Application," Bingjing: Science Press, 2003.

[2] J. W. Jung, Y. S. Choi, V. Q. Leu, et al., "Fuzzy PI-type current controllers for permanent magnet synchronous motors," IET Electric Power Applications, vol, 5, pp. 143-152, 2011.

[3] W. Zhang, and J.Q. Mao, "Adaptive fuzzy sliding mode control method based on fuzzy tree model," Control Theory \& Applications, vol, 17, pp. 263-268, 2010.

[4] X. Luo, Z. Zhu, and X. Guan, "Nonlinear time delay systems chattering weakened adaptive sliding control," Control \& Decision, vol, 24, pp. 1429-1435, 2009.
[5] I. C. Baik, K. H. Kim, and M. J. Youn, "Robust nonlinear speed control of PM synchronous motor using boundary layer integral sliding mode control technique," IEEE Transactions on Control Systems Technology, vol. 8, pp. 47-54, 2000.

[6] Y. Fang, Z. Li, Y. Wu, and X. Yu, "Backstepping control of PMSM position systems based onterminal- slideing-mode load observer," Electric Machines and Control, vol. 18, pp. 105-111, 2014

[7] L. Da, and X. Wang, "Observer-based decentralized fuzzy neural sliding mode control for interconnected unknown chaotic systems via network structure adaptation," Fuzzy Sets and Systems, vol. 16, pp. 2066- 2080, 2010.

[8] F. Dinuzzo, and A. Ferrara, "Higher order sliding mode controllers with optimal reaching," IEEE Transactions on Automatica Control, vol. 54, pp. 98-104, 2009.

[9] A. Levant, "Homogeneity approach to high-order sliding mode design," Automatica, vol. 41, pp. 823-830, 2005.

[10] Boiko, L. Fridman, and M. I. Castellanos, "Analysis of second order sliding mode algorithms in the frequency domain," IEEE Transactions on Automatic Control, vol. 49, pp. 946-950, 2004.

[11] M. Magdy, "Abdelhameed enhancement of sliding mode controller by fuzzy logic with application to robotic manipulators," Mechatronics, vol. 15, pp. 439-458, 2005.

[12] R.J. Wai, "Fuzzy sliding-mode control using adaptive tuning technique," IEEE Transactions on Industrial Electronics, vol. 54, pp. 78-87, 2007.

[13] F. J. Lin, and P. H. Shen, "Robust fuzzy neural network slidingmode control for two-axis motion control system," IEEE Transactions on Industrial Electronics, vol. 53, pp. 1209-1225, 2006.

[14] C. Yeroglu, and N. Tan, "Note on fractional-order proportionalintegral-differential controller design," IET Control Theory and Applications, vol. 5, pp. 1978-1989, 2011.

(C) Huang and Zuo; Licensee Bentham Open.

This is an open access article licensed under the terms of the Creative Commons Attribution Non-Commercial License (http://creativecommons.org/licenses/by$\mathrm{nc} / 3.0 /$ ) which permits unrestricted, non-commercial use, distribution and reproduction in any medium, provided the work is properly cited. 